\title{
Oestradiol-17 $\beta$ both inhibits and stimulates myometrial activity in ewes in vivo
}

\author{
S. J. Lye*, D. Claire Wathes and D. G. Porter \\ Pre-Clinical Veterinary Studies, Department of Anatomy, The Medical School, Bristol BS8 1TD, \\ U.K.
}

\begin{abstract}
Summary. Spontaneous intrauterine pressure cycles were abolished for periods of several hours in ovariectomized non-pregnant ewes within $8 \mathrm{~h}$ of an injection of $50 \mu \mathrm{g}$ oestradiol-17 $\beta$. Following the quiescent period, a phase of intense uterine activity ensued for several hours before again being replaced by several hours of quiescence. This active/inactive cycle disappeared after 2-4 days if further daily injections of oestradiol were not given. During the quiescent periods the uterus retained its responsiveness to oxytocin and PGF- $2 \alpha$. Increasing the dose of oestradiol failed to prolong the periods of quiescence.
\end{abstract}

\section{Introduction}

During daily routine recording of intrauterine pressure for periods of $1-2 \mathrm{~h}$ from conscious ovariectomized ewes treated with oestradiol $(50 \mu \mathrm{g} /$ day s.c.) we noticed that myometrial activity was erratic. For example a ewe might exhibit intrauterine pressure cycles of high amplitude $(\sim 45$ $\mathrm{mmHg}$ ) and high frequency (50 cycles/15 min) at 09:00 h and yet have no demonstrable uterine activity at $17: 00 \mathrm{~h}$ or at $09: 00 \mathrm{~h}$ the next day. As these observations were made during short (1-2 h) periods of recording we investigated the problems more fully by monitoring intrauterine pressure continuously for longer periods.

\section{Materials and Methods}

Ten Clun Cross ewes aged 4-7 years with a history of normal fecundity were ovariectomized bilaterally and equipped with intrauterine recording balloons according to the method described elsewhere (Lye \& Porter, 1978). In addition the ewes received an indwelling Silastic catheter (Dow Corning, Midland, Michigan, U.S.A.; i.d. $2.64 \mathrm{~mm}$; o.d. $4.88 \mathrm{~mm}$ ) in one jugular vein. The animals were injected daily from the time of surgery with $50 \mu \mathrm{g}$ oestradiol-17 $\beta$ (Sigma Chemical, London) in $\mathbf{0 . 2 5} \mathrm{ml}$ corn oil. They were allowed at least 4 days to recover from surgery during which time they received antibiotic treatment $(7 \mathrm{ml}$ Strypen, May \& Baker Ltd, Dagenham, Essex, i.m. daily for 5 days) before intrauterine pressure was monitored by connecting the balloon catheters to Bell and Howell pressure transducers, interfaced with an Ormed MX4 pen recorder (Ormed, Welwyn Garden City, Herts). Intrauterine pressure was monitored daily for several days to determine that spontaneous activity was present before oestrogen treatment was discontinued. The appearance of continuous intrauterine pressure cycles of low amplitude was taken as the time for

*Present address: Department of Obstetrics \& Gynaecology, University of Western Ontario, London, Canada N6A 5A5. 
the resumption of oestradiol treatment. Although this interval varied by up to 3 days among ewes, this was inevitable if a consistent level of uterine activity was to be used as a starting point. It is unlikely that this would have lead to marked differences in uterine atrophy among the ewes as de Mattos, Kempson, Erdos \& Csapo (1967) have shown that the presence of an intrauterine balloon markedly retards the process of uterine atrophy in ovariectomized animals. During the recording sessions, which lasted up to $24 \mathrm{~h}$ per day for up to 5 days, the ewes were kept in wooden crates which were large enough to permit them to lie or stand but not to turn round, although some forward and backward movement was possible. The ewes adapted readily to this restraint and showed no behavioural signs of stress. The experiments were conducted between February and April so that the animals received 11-14 h daylight per $24 \mathrm{~h}$. The animals had access to water and hay at all times. Individual ewes were used in several treatment protocols but at least 5 days were always allowed to elapse between the end of one protocol and the beginning of the next. Animals were assigned to one of the following 3 categories.

\section{Treatment I}

In 6 ewes which had not received oestradiol treatment for at least 7 days intrauterine pressure was recorded for $2-3$ days. Then injections of $50 \mu \mathrm{g}$ oestradiol-17 $\beta$ in $0.25 \mathrm{ml}$ corn oil s.c. were given daily for 3 days at $08: 00 \mathrm{~h}$. In 2 of the ewes at $0,4,8,12$ and $15 \mathrm{~h}$ after the initial oestrogen injection the chart speed of the pen recorder was increased to $100 \mathrm{~mm} / \mathrm{sec}$. This enabled the rate of rise of pressure of each intrauterine pressure cycle to be determined by calculating the ratio of the maximum amplitude of pressure to the time taken for the pressure to peak after rising from the baseline. Whenever possible the mean rate of rise of pressure of 10 cycles was determined.

\section{Treatment II}

Four ewes received oestradiol injections as in Treatment I. However, when spontaneous pressure cycles had been abolished each ewe received an injection of $250 \mathrm{mu}$ oxytocin (Syntocinon; Sandoz, Feltham, Middlesex) via the jugular catheter, or, in a separate series of experiments, received an intrauterine infusion of PGF- $2 \alpha(27 \mu \mathrm{g}$ Dinoprost/min; Upjohn, Crawley, Sussex).

\section{Treatment III}

Four ewes received the following 3 treatment protocols in succession with a 5-day recovery between each: (i) $25 \mu \mathrm{g}$ oestradiol- $17 \beta$ in $0.25 \mathrm{ml}$ corn oil (s.c.) every $4 \mathrm{~h}$ for 4 occasions; (ii) $100 \mu \mathrm{g}$ in oestradiol-17 in $0.5 \mathrm{ml}$ corn oil (s.c.) at $08: 00,16: 00$ and $23: 00 \mathrm{~h}$; and (iii) $50 \mu \mathrm{g}$ oestradiol benzoate (Sigma Chemicals, London) daily in $0.25 \mathrm{ml}$ corn oil (s.c.).

Intrauterine pressure records were divided into $15 \mathrm{~min}$ intervals and analysed for maximum amplitude and frequency of pressure cycles.

\section{Plasma oestradiol measurements}

Method. Blood samples were obtained from 4 additional ewes treated identically to those in Treatment I (except that no intrauterine pressure records were taken) at $0,1,2,3,4,5,6,8,12$, and $24 \mathrm{~h}$ after the first oestradiol injections. The samples were collected in heparinized vacuum tubes and centrifuged at $4^{\circ} \mathrm{C}$. Plasma was separated and stored at $-20^{\circ} \mathrm{C}$ until oestradiol-17 $\beta$ was measured by radioimmunoassay.

Plasma samples ( $1 \mathrm{ml}$ in duplicate) were transferred to test tubes and extracted with $4 \mathrm{ml}$ diethyl ether (Analar, BDH, Poole, Dorset, U.K.) from a freshly opened bottle for $5 \mathrm{~min}$ on a Denley multivortex mixer at a speed of 20 . Samples were frozen at $-15^{\circ} \mathrm{C}$ for $30 \mathrm{~min}$, before the organic phase was decanted to a second set of tubes and evaporated to dryness. Recovery of oestradiol-17 
during this extraction procedure was estimated as follows: $\left[{ }^{3} \mathrm{H}\right]$ oestradiol- $17 \beta(0 \cdot 1 \mathrm{ml}$ in ethanol) was added to 8 extraction tubes and dried down. Plasma $(1.0 \mathrm{ml})$ was added to each tube and these were mixed and incubated at $30^{\circ} \mathrm{C}$ for $15 \mathrm{~min}$ before ether extraction. A stock solution of $100 \mu \mathrm{g}$ oestradiol-17/ (Sigma Chemicals, London) $/ \mathrm{ml}$ ethyl alcohol was diluted to give a solution of $5 \mathrm{ng} / \mathrm{ml}$ in phosphate-buffered saline (PBS, $0.1 \mathrm{M}, \mathrm{pH} 7.1$ containing $0.1 \%$ of both gelatin and sodium azide). This was serially diluted in buffer to give 9 standards ranging from 500 to $1.9 \mathrm{pg}$ per $0.1 \mathrm{ml}$ plus a tenth containing buffer only; $100 \mu \mathrm{l}$ of each were pipetted into assay tubes in triplicate. Buffer $(100 \mu \mathrm{l})$ was added to each of the extracted samples to equalize the reagent volumes before $100 \mu \mathrm{l}$ antiserum (courtesy Dr J. R. G. Challis; sheep 20-102) were added to all samples and standards at a concentration of $1: 13000$. After this $100 \mu \mathrm{l}\left[2,3,6,7-{ }^{3} \mathrm{H}\right]$ oestradiol- $17 \beta$ (sp. act. 4 $\mathrm{TB}_{2} / \mathrm{mmol}$ : Radiochemical Centre, Amersham, Bucks, U.K.) were added at a concentration of 100 c.p.m. $/ \mu \mathrm{l}$. All tubes were vortexed and left to incubate overnight at $4^{\circ} \mathrm{C}$.

To separate bound and free steroid $100 \mu 10.5 \%$ gelatin in PBS were added to each tube, followed by activated charcoal (Sigma Chemical, London) and $0.1 \%$ dextran (clinical grade, Sigma Chemical, London) in $0.5 \mathrm{ml}$ PBS. The tubes were incubated for $10 \mathrm{~min}$ at $4^{\circ} \mathrm{C}$ and centrifuged at $1500 \mathrm{~g}$ for a further $10 \mathrm{~min}$ at $4^{\circ} \mathrm{C}$. The supernatants were decanted into small scintillation tubes, and $2.5 \mathrm{ml}$ scintillation fluid were added to each $(0.4 \%$ PPO (Fisons, Loughborough, Leics) in toluene). The tubes were incubated at $70^{\circ} \mathrm{C}$ for $20 \mathrm{~min}$, capped and vortexed, and the labelled oestradiol was allowed to equilibrate between the aqueous and organic phases. The tubes were then counted for $5 \mathrm{~min}$ on a liquid scintillation spectrometer (Packard). All samples from the same sheep were analysed in the same assay.

Validation. Steroids tested which had $>0.1 \%$ cross-reactivity with the antiserum were as follows: oestrone, $9 \cdot 2 \%$; oestradiol benzoate, $2.7 \%$; oestriol, $0.7 \%$; testosterone, $0.3 \%$; androsterone, $0.3 \%$; dehydroepiandrosterone sulphate, $0.2 \%$. Solvent blanks contained $<4 \mathrm{pg} /$ tube, and water blanks $<6 \mathrm{pg} /$ tube. Sensitivity, defined as twice the s.d. of the zero value was $4.9 \mathrm{pg}(10$ assays). The recovery of radioactive oestradiol-17 $\beta$ from $1 \mathrm{ml}$ aliquants of plasma was $77 \cdot 7 \pm 3 \cdot 54 \%$ (s.e.m., 8 assays). Accuracy was assessed by adding known amounts of oestradiol-17ß to $1 \mathrm{ml}$ aliquants of plasma from an ovariectomized sheep which contained $2.8 \pm 0.17 \mathrm{pg}$ oestradiol$17 \beta / \mathrm{ml}$. The mean concentrations for 4 or 5 samples in each determination were : $7 \cdot 8 \mathrm{pg}$ added, 13.1 $\pm 3.98 \mathrm{pg}$ measured $(124 \%$ recovery) $; 31.2 \mathrm{pg}$ added, $32.3 \pm 8.02 \mathrm{pg}$ measured $(95 \%$ recovery) $; 125$ pg added, $133.8 \pm 5 \cdot 10 \mathrm{pg}$ measured (105\% recovery) and $250 \mathrm{pg}$ added, $196.9 \pm 8.98 \mathrm{pg}$ measured ( $78 \%$ recovery). The inter- and intra-assay coefficients of variation were $14.1 \%$ and $14.5 \%$ respectively. Plasma samples taken from one ewe at 5 -h intervals during parturition showed a peak in oestradiol-17 $\beta$ rising from undetectable levels 5 days before parturition to $128 \mathrm{pg} / \mathrm{ml}$ at $12 \mathrm{~h}$ before and falling again to $3.6 \mathrm{pg} / \mathrm{ml}$ by $12 \mathrm{~h}$ post partum. These values closely resemble those reported by Challis (1971).

\section{Results}

All ewes treated with oestradiol exhibited a qualitatively similar myometrial response.

\section{Treatment $I$}

All ewes in this group exhibited a similar pattern of myometrial activity during the period before oestrogen administration. This consisted of an almost continuous series of low-amplitude low-frequency intrauterine pressure cycles. After oestrogen treatment myometrial activity in all ewes declined and the uterus became quiescent. Total quiescence supervened in $306 \pm 54$ min (mean \pm s.e.m., $n=4$ ), and lasted for $431 \pm 41$ min before uterine mechanical activity reappeared. The activity then increased markedly both in frequency and amplitude and pressure cycles occurred at a higher rate and amplitude than before oestrogen treatment (Text-fig. 1). The periods 
of intense activity were limited, having a mean \pm s.e.m. duration of $462 \pm 74$ min since they alternated with further periods of quiescence of a mean \pm s.e.m. duration of $198 \pm 10$ min over 48 $h$. The two uterine horns of each ewe behaved similarly, i.e. both were quiescent or active at the same time. In 2 ewes the rates of rise of intrauterine pressure were determined and were significantly greater during the hyperactive phase following oestradiol treatment $(463 \pm 16$ $\mathrm{mmHg} / \mathrm{min})$ than before treatment $(245 \pm 26 \mathrm{mmHg} / \mathrm{min}: P<0.002$; paired $t$ test $)$.

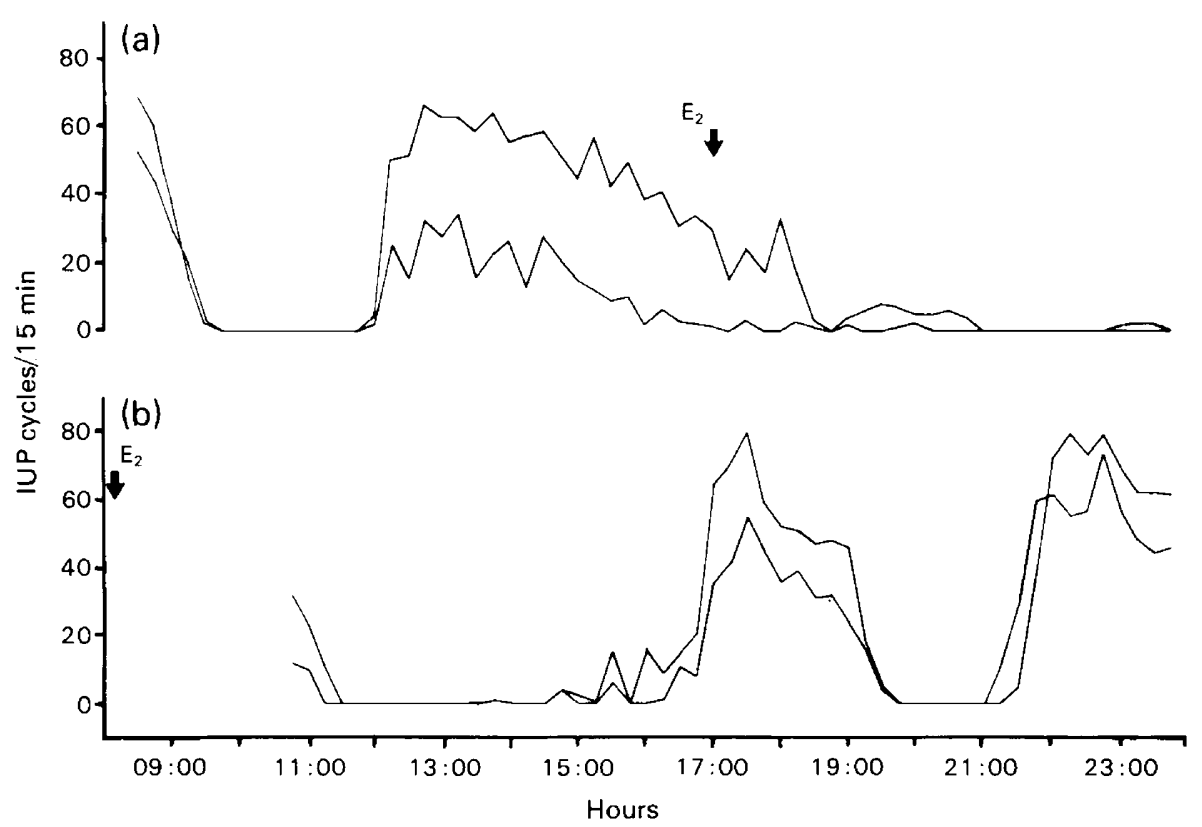

Text-fig. 1. Frequency of intrauterine pressure cycles in the two uterine horns of an ovariectomized ewe given $50 \mu \mathrm{g}$ oestradiol s.c. at (a) 17:00 h and (b) 08:00 h in separate experiments. Note the long periods of quiescence which occur in both horns within $4-6 \mathrm{~h}$ of oestradiol administration and the phases of intense activity which interrupt the quiescence.

\section{Treatment II}

In all 4 ewes the myometrium responded markedly during the oestrogen-induced quiescent periods to intravenous injections of oxytocin $(250 \mathrm{mu})$ or intrauterine infusions of PGF- $2 \alpha(27$ $\mu \mathrm{g} / \mathrm{min})$.

\section{Treatment III}

None of the dose regimens adopted for oestradiol-17 $\beta$ nor the use of oestradiol benzoate appeared to alter the duration of the quiescent periods beyond that induced by a single injection of $50 \mu \mathrm{g}$ oestradiol-17 3 (Treatment I). Indeed in ewes given $100 \mu \mathrm{g}$ oestradiol-17 $\beta$ every $8 \mathrm{~h}$ the duration of the first quiescent period was shorter, i.e. 60-120 min than after $50 \mu \mathrm{g}(431 \mathrm{~min})$. Moreover, the alternation of active/inactive periods was far less obvious (Text-fig. 2) than at the lower dose. Oestradiol benzoate injection was followed by an initial quiescent period of about 240 min but thereafter the clear distinction between active and inactive periods was again blurred and neither frequency nor amplitude achieved the high levels seen after $50 \mu \mathrm{g}$ oestradiol. 


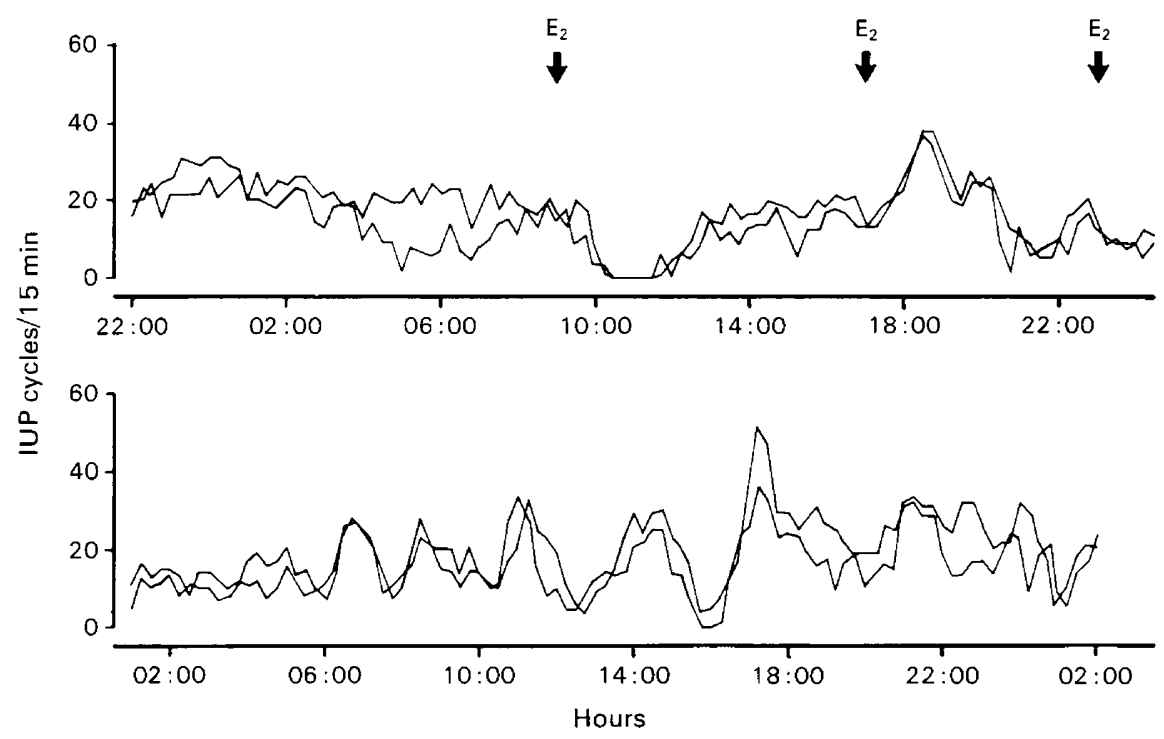

Text-fig. 2. Frequency of intrauterine pressure cycles in the two uterine horns of a ewe treated with 3 injections of $100 \mu \mathrm{g}$ oestradiol-17 $\beta$ s.c. as indicated by arrows. Compare with Text-fig. 1 .

\section{Oestradiol measurements}

Among the 4 ewes sampled after a single injection (s.c.) of $50 \mu \mathrm{g}$ oestradiol- $17 \beta$ at $0 \mathrm{~h}$, mean \pm s.e.m. plasma oestradiol titres $(\mathrm{pg} / \mathrm{ml})$ were as follows : $<5$ at $0 \mathrm{~h} ; 5.2 \pm 1.9$ at $1 \mathrm{~h} ; 11.4 \pm 3.6$ at $2 \mathrm{~h}$; $11.7 \pm 4.9$ at $3 \mathrm{~h} ; 9.8 \pm 0.9$ at $4 \mathrm{~h} ; 12.9 \pm 1.0$ at $5 \mathrm{~h} ; 11.6 \pm 1.8$ at $6 \mathrm{~h} ; 5.9 \pm 2.2$ at $8 \mathrm{~h} ; 5.7 \pm 3.3$ at $12 \mathrm{~h}$ and $<5$ at $24 \mathrm{~h}$.

\section{Discussion}

By recording intrauterine pressure continuously from conscious ovariectomized ewes over long periods we have revealed that a distinctive pattern of uterine activity develops in response to injections of oestradiol. When oestrogen is withheld from such ewes the uterus exhibits continuous, low-level activity which usually declines over a period of about 2 weeks. However, if oestradiol is administered the continuous activity gives way to complete inactivity for an initial period of several hours, followed by prolonged periods of intense activity interspersed with further periods of quiescence. The long periods of quiescence or activity explain the apparently erratic behaviour of the uterus which we had observed in ewes in which myometrial activity was recorded only for periods of 1-2 h/day. Although the cycles of active/inactive periods appear to occur at similar times of the day in different ewes after oestradiol injections at $08: 00 \mathrm{~h}$, this pattern differed from that which followed an injection time of $17: 00 \mathrm{~h}$ in pilot experiments. This suggested that it was not an endogenous circadian rhythm but was related to the time of hormone administration.

The first period of total quiescence occurred in the present experiments about $5 \mathrm{~h}$ after the oestradiol injections, at a time when plasma titres of oestradiol were elevated, lasted for about $7 \mathrm{~h}$, and then recurred again after a period of intense uterine activity of several hours when oestradiol titres were low. This alternation of behaviour disappeared after 2-4 days if further injections of oestradiol were not given but, from our experience of recording for short sessions from ewes treated with oestradiol daily over a long period, it seems probable that this alternating pattern could be sustained for at least several months.

Although these changes clearly occur in response to oestrogen injections it was not possible to 
correlate them with the plasma concentrations of the steroid. However, the measurements made in ewes undergoing Treatment I indicate that the response is related to physiological titres of oestradiol: plasma titres did not exceed $24 \mathrm{pg} / \mathrm{ml}$ in any sample taken during the $24 \mathrm{~h}$ after oestradiol treatment.

Inhibition of the myometrium by oestradiol has not been reported before in sheep although Coutinho \& de Mattos (1968) have described inhibitory effects of the steroid on the uterus in rabbits and Burns (1972), Fuchs $(1974,1976)$ and Downing, Lye, Bradshaw \& Porter (1978) have published similar findings in rats. Although there are some differences in detail in the effects of oestradiol among the three species, in all of them the response to oxytocin appears to be spared when spontaneous activity is abolished or markedly reduced. In the ewe, as in the rat (Downing $e t$ al., 1978; Wathes \& Porter 1982), during recovery from oestrogen-induced quiescence the rate of rise of intrauterine pressure during spontaneous pressure cycles increased significantly. In the intact pig also, myometrial activity appears to exhibit alternation of activity and quiescence during the period of rising oestrogen levels in early oestrus (M. A. M. Taverne, personal communication).

A surprising feature of the action of oestradiol on the ovine uterus which occurs also in the pig (M. A. M. Taverne, personal communication) is the recurrence of periods of quiescence after the uterus has resumed spontaneous activity after the initial quiescent phase. Although this has not been reported for rabbits and rats it is possible that it may have been missed due to the relatively shorter daily recording periods used for the former (Coutinho \& de Mattos, 1968) and in the latter by the very much longer periods of quiescence which are only interrupted from time to time by bursts of activity of short duration (Downing et al., 1978).

The mechanism by which oestradiol exerts its biphasic action is unknown. Although it is possible to postulate mechanisms to account separately for the inhibition, e.g. synthesis of an inhibitory substance in response to oestrogen and for the periods of enhanced activity, e.g. prostaglandin (PG) secretion, or increased population of oxytocin receptors (Alexandrova \& Soloff, 1980), it is very difficult to postulate a mechanism which would account for the alternation of these two states. Unpublished experiments (Lye, 1980) in which oestrogen-treated ewes were infused with the PG synthetase inhibitor, meclofenamic acid, suggested that this oestrogen-induced pattern of activity was prostaglandin-dependent, since both the high-activity and quiescent periods were abolished by this drug. The myometrial stimulatory effects of prostaglandins in sheep are well known (see Lye \& Porter, 1978) and Lye \& Challis (1982) have shown that prostacyclin (PGI-2) can inhibit spontaneous uterine activity in sheep.

Possible mechanisms should take account of catecholamines. Myometrial activity is inhibited by adrenaline in rats (Gaddum, Peart \& Vogt, 1949; Levy \& Tozzi, 1963; Vesin \& Harbon, 1974) and oestrogen increases the uterine content of adrenaline in that species (Spratto \& Miller, 1968a, b). However, Downing \& Porter (1980) found that neither depletion of uterine catecholamine stores with reserpine no blockade of $\alpha$ or $\beta$ adrenoreceptors altered the extent or the time course of oestradiol inhibition in rats. Also, although administration of adrenaline as an intravenous bolus of $0.2 \mathrm{mg}$ ( 3 ewes) or by intrauterine infusion ( 1 ewe) of up to $100 \mu \mathrm{g} / \mathrm{min}$ abolished spontaneous uterine activity, it also blocked the response to oxytocin (S. J. Lye \& D. G. Porter, unpublished data).

The suggestion has been made (Porter, 1979) that oestradiol-induced inhibition of myometrial activity may be mediated by relaxin synthesized in the uterus. There is no evidence for or against the existence of such a mechanism in the ewe although relaxin (porcine) inhibits the spontaneous activity of the ovine myometrium in vivo (Porter, Lye, Bradshaw \& Kendall, 1981) and leaves the response to oxytocin unimpaired. Moreover, uterine synthesis of relaxin has been reported for the guinea-pig (Nagao \& Bryant-Greenwood, 1981; Pardo \& Larkin, 1982).

We thank Mrs Wendy Sansum for skilled technical assistance; the A.R.C. for research grants; Mrs S. Somers for typing the manuscript; and Dr J. R. G. Challis for a generous gift of oestradiol antiserum. 


\section{References}

Alexandrova, M. \& Soloff, M.S. (1980) Oxytocin receptors and parturition. I. Control of oxytocin receptor concentration in the rat myometrium at term. Endocrinology 106, 730-735.

Burns, J.K. (1972) Effects of single or combined oestrogens and of ovariectomy on rat uterine contractility J. Physiol., Lond. 225, 46P-47P.

Challis, J.R.G. (1971) Sharp increase in free circulating oestrogen immediately before parturition in sheep. Nature, Lond. 229, 208.

Coutinho, E.M. \& de Mattos, C.E.R. (1968) Effects of oestrogen on the motility of the non-atrophic estrogen deficient rabbit uterus. Endocrinology 83, 422-432.

de Mattos, C.E.R., Kempson, R.L., Erdos, T. \& Csapo, A. (1967) Stretch-induced myometrial hypertrophy. Fert. Steril. 18, 545-556.

Downing, S.J. \& Porter, D.G. (1980) Oestrogen-induced myometrial quiescence in the post-partum rat is not mediated by adrenaline or by $\alpha$ or $\beta$-adrenoceptor activation. J. Endocr. 85, 405-413.

Downing, S.J., Lye, S.J., Bradshaw, J.M.C. \& Porter, D.G. (1978) Rat myometrial activity in vivo: effects of oestradiol-17 $\beta$ and progesterone in relation to the concentrations of cytoplasmic progesterone receptors. J. Endocr. 78, 103-117.

Fuchs, A.-R. (1974) Myometrial response prostaglandins enhanced by progesterone. Am. J. Obstet. Gynec. 118, 1093-1098.

Fuchs, A.-R. (1976) Influence of estrogen and progesterone on uterine motility reassessed. Gynec. Invest. 7 , 99, Abstr.

Gaddum, J.H., Peart, W.S. \& Vogt, M. (1949) The estimation of adrenaline and allied substances in blood. J. Physiol., Lond. 108, 467-481.

Levy, B. \& Tozzi, S. (1963) The adrenergic receptive mechanism of the rat uterus. J. Pharmacol exp. Ther. 142, 178-184.

Lye, S.J. (1980) The hormonal control of myometrial activity in the sheep and rat. Ph.D. thesis, University of Bristol.
Lye, S.J. \& Challis, J.R.G. (1982) Inhibition by PGI-2 of myometrial activity in vivo in non-pregnant ovariectomized sheep. J. Reprod. Fert. 66, 311-315.

Lye, S.J. \& Porter, D.G. (1978) Demonstration that progesterone 'blocks' uterine activity in the ewe in vivo by a direct action on the myometrium. J. Reprod. Fert. 52, 87-94.

Nagao, R. \& Bryant-Greenwood, G.D. (1981) Evidence for a uterine relaxin in the guinea pig. In Relaxin, $\mathrm{pp}$. 6I-66. Eds G. D. Bryant-Greenwood, H. D. Niall \& F. C. Greenwood. Elsevier/North Holland, Amsterdam.

Pardo, R.J. \& Larkin, L.H. (1982) Localization of relaxin in endometrial gland cells of pregnant, lactating and ovariectomized hormone-treated guinea pigs. Am. J. Anat. 164, 79-90.

Porter, D.G. (1979) The myometrium and the relaxin enigma. Anim. Reprod. Sci. 2, 77-96.

Porter, D.G., Lye, S.J., Bradshaw, J.M.C. \& Kendall, J.Z. (1981) Relaxin inhibits myometrial activity in the ovariectomized non-pregnant ewe. J. Reprod. Fert. 61, 409-414.

Spratto, G.R. \& Miller, J.W. (1968a) The effect of various estrogens on the weight, catecholamine content and rate of contractions of rat uteri. $J$. Pharmacol. exp. Ther. 161, 1-6.

Spratto, G.R. \& Miller, J.W. (1968b) An investigation of the mechanism by which estradiol-17 $\beta$ elevates the epinephrine content of the rat uterus. J. Pharmacol. exp. Ther. 161, 7-13.

Vesin, M.F. \& Harbon, S. (1974) The effects of epinephrine, prostaglandins and their antagonists on adenosine 3'5'monophosphate concentrations and motility of the rat uterus. Molec. Pharm. 10, 457-473.

Wathes, D.C. \& Porter, D.G. (1982) Effect of uterine distension and oestrogen treatment on gap junction formation in the myometrium of the rat. J. Reprod. Fert. 65, 497-505.

Received 1 July 1982 